Mattos MR. et.al, J Community Med Public Health 5: 227.

www.doi.org/10.29011/2577-2228.100227

www.gavinpublishers.com

\title{
Economic Burden of Tuberculosis for Patients
}

\section{and their Households in Cochabamba, Bolivia}

\section{Marcelo Rojas Mattos ${ }^{1,2 *}$, Daniel Illanes ${ }^{2}$, Jorge Avilez $^{2}$, Wilson Trujillo ${ }^{2}$, Anandi Martin', Annie Robert ${ }^{1}$}

'Institut de Recherche Expérimentale et Clinique (IREC) Pôle de Recherche en Epidémiologie et Biostatistique, Université catholique de Louvain UCLouvain, Brussels, Belgium

${ }^{2}$ Instituto de Investigaciones Biomédicas IIBISMED, Universidad Mayor de San Simón (UMSS), Cochabamba, Bolivia

"Corresponding author: Marcelo Rojas Mattos, Institut de Recherche Expérimentale et Clinique (IREC) Pôle de Recherche en Epidémiologie et Biostatistique, Université catholique de Louvain UCLouvain, Brussels, Belgium.

Citation: Mattos MR, Illanes D, Avilez J, Trujillo W, Martin A, et al. (2021) Economic Burden of Tuberculosis for Patients and their Households in Cochabamba, Bolivia. J Community Med Public Health 5: 227. DOI: 10.29011/2577-2228.100227

Received Date: 07 December 2021; Accepted Date: 13 December, 2021; Published Date: 17 December 2021

\begin{abstract}
Background: Patients with tuberculosis (TB) usually incur large costs directly related to their disease. Additional indirect costs also increase the economic burden of households creating barriers of access and adherence that can affect the healing of patients. Because TB affects the poorest segment of society the effects can be more serious for poor people. Indirect costs are poorly documented in Bolivia. We therefore conducted a study to determine the socioeconomic impact of TB on patients and their households.

Methods: A cross-sectional survey was carried out on 2017 in the Department of Cochabamba, Bolivia, included all patients who were on TB treatment within the health network. The generic survey instrument proposed by WHO for tuberculosis patients cost surveys was used. The most important direct medical and direct non-medical payments were calculated in a disaggregated manner. The calculation of indirect costs was carried out through the results-based approach where the loss of income was calculated from the report of household income. Catastrophic cost was determined and multivariable logistic regression was run to assess which factors were independently associated with a total catastrophic cost experienced by a TB patient.

Results: The indirect costs during an entire illness episode had a median of USD 768.1 corresponding to $63.4 \%$ of the total cost for all patients. In the case of multidrug-resistant TB (MDR TB) patients, the median cost was USD 6454.8 corresponding to $54.3 \%$ of their total costs. Direct non-medical costs had a median for all patients of USD 408.7 (33.7\%), and of USD 5399.6 (45.4\%) for MDR TB patients. The most important non-medical costs were those linked to directly observed treatment (DOT) with a median of USD 419.8 during intensive phase and of USD 108.6 during continuation phase for transport costs. Food and drinks costs had a median of USD 94.5 during intensive phase and of USD 54.8 during continuation phase; consumption of nutritional supplements had a median cost of USD 249.1 and additional food outside the regular diet had a median cost of USD 519 for all patients. Catastrophic costs were incurred by $43.9 \%$ of TB patients. These catastrophic costs were observed in $50 \%$ of the population aged over 55 years, in $60 \%$ of MDR-TB patients, and in $63 \%$ of poor patients. Using logistic regression, factors associated with a higher risk of catastrophic costs were to live in an urban province $(\mathrm{OR}=1.8295 \% \mathrm{CI} 1.11$ to $2.98, \mathrm{P}=$ $0.002)$, to be older than 55 years $(\mathrm{OR}=1.2195 \% \mathrm{CI}$ : 1.07 to $1.38, \mathrm{P}=0.005)$, and to have a low economic income $(\mathrm{OR}=0.83$ $95 \%$ CI: 0.69 to $0.99, \mathrm{P}=0.049$ ).

Conclusions: Patients with TB treated in health services of Bolivia face a great financial burden. Indirect costs were higher than direct costs in a complete TB episode, especially in MDR-TB patients. During the treatment, the most important costs were those related to transport and food when patients went to DOT; nutritional supplements and additional food to the regular diet accounted also for a non-negligible cost. Almost half of patients suffer a catastrophic cost, especially those who came from an urban province, those who were older than 55 years, and those having a low economic income.
\end{abstract}


Citation: Mattos MR, Illanes D, Avilez J, Trujillo W, Martin A, et al. (2021) Economic Burden of Tuberculosis for Patients and their Households in Cochabamba, Bolivia. J Community Med Public Health 5: 227. DOI: 10.29011/2577-2228.100227

Keywords: Tuberculosis; Direct costs; Indirect costs; Catastrophic costs; Logistic regression

\section{Introduction}

Tuberculosis (TB) is a neglected disease; it is the ninth leading cause of death in the world and the leading cause of death due to an infectious disease, surpassing even HIV / AIDS [1]. In 2019, an estimated 10 million people developed the disease and 1.4 million die of TB, with most cases occurring in developing countries. In 2016, in the region of the Americas the incidence rate was 27 cases / 100,000 inhabitants. However, in South America, Bolivia ranked second in the incidence of TB, with a rate of 114 cases / 100,000 inhabitants [2]. In the Department of Cochabamba in Bolivia, the TB incidence was 60 cases / 100,000 inhabitants, according to data from the TB Control Program of the Departmental Health Service [3].

The Bolivian health system has three sectors: the public, the private and the social security sector [4]. The levels of medical care are organized in a pyramidal model with first, second and third level of care. The TB Control Program carries out the diagnosis and treatment of TB and is implemented in the public health sector where any person suspected of tuberculosis should be diagnosed and treated. From a case definition perspective, TB can be classified as a bacteriologically confirmed TB or as a clinically diagnosed TB. These types, in turn, are classified according to the anatomic location into pulmonary or extrapulmonary tuberculosis [5]. The diagnosis is made by bacteriological methods such as smear, culture and molecular biology, and it can also be done by imaging and pathological studies, especially in cases of extrapulmonary tuberculosis. Sensitivity and resistance tests are also performed in patients at risk of developing drug resistance [5]. Patients with TB are treated with first-line medications and patients with resistant TB are treated with second-line medications. The treatment of TB is carried out in two phases, the intensive phase that lasts 2 months with the administration of 4 antibiotics, and the continuation phase that lasts 4 months with only 2 administrated antibiotics. The Directly Observed Treatment (DOT) is the strategy used by health personnel to guarantee the taking and compliance of the treatment until its completion and cure [5].

Patients with TB usually incur large costs related to their disease, since they begin with the symptoms looking for the solution to their health problem, even when they are already diagnosed and treated within the health system, despite the fact that the diagnosis and the treatment are free. These costs can create barriers of access and adherence that can affect the healing of patients and that can increase the risk of disease transmission. In low and middleincome countries, TB patients suffer costs that are on average, the same amount as half of their annual income [6]; therefore, the aforementioned costs also increase the economic burden of households. In all contexts, TB affects the poorest segment of society. Therefore, the aggravating effects of poverty due to TB are even more serious for those who are already the most vulnerable. The out-of-pocket medical expenses of these patients, which are made worse by the loss of their income, can be significant [7]. This is often a factor contributing to economic difficulties. Direct non-medical costs, such as transportation and food costs during the period of seeking health care, can also be significant considering that this period is often long because a treatment period lasts from six months to two years [6]. To overcome the barriers of access and adherence, as well as minimize the economic burden for patients with TB (and their households), it is essential to address both direct and indirect costs. Interventions are necessary to address high medical costs, as well as food and transportation costs, and lost economic income. Therefore, both financing and health service delivery models and social protection mechanisms must be considered [8]. One of the three objectives of the "End Tuberculosis Strategy" launched by the WHO is that no patient with TB or their households should face "total catastrophic costs" (expenses beyond a defined threshold of the ability to payment of a household) due to TB and this objective should be achieved until the year 2035 [9]. The objective of the present study was to assess the socioeconomic impact of TB on patients and their households through the magnitude and the main causes of direct and indirect costs, and to estimate the catastrophic total costs incurred by TB patients in order to build strategies for improving adherence to treatment and financial protection of persons in Bolivia.

\section{Material and Methods}

A cross-sectional survey with retrospective data collection was carried out in January 2017, using the protocol proposed by the WHO Global TB Program for survey to determine direct and indirect costs due to TB and to estimate proportion of TB-affected households experiencing catastrophic total costs due to TB [10].

\section{Survey Population}

The survey population included all patients (even children accompanied by a guardian) who were on drug-susceptible DS-TB or multi-drug resistant tuberculosis (MDR-TB) treatment, either in the continuation or in the intensive phase, within the public health services network, which is the only one in charge of carrying out the diagnosis and treatment of all patients with tuberculosis. The impact of TB costs was analyzed at the household level, so if more than one household member was registered for treatment, costs for all the patients in that household were estimated by interviewing all household members on treatment.

\section{Inclusion and exclusion criteria}

Eligible patients were all patients registered for a TB treatment on January 2017 in the Department of Cochabamba in Bolivia, regardless of age, and whether they were affected by drug-susceptible or resistant $\mathrm{TB}$, who were attending a sampled 
Citation: Mattos MR, Illanes D, Avilez J, Trujillo W, Martin A, et al. (2021) Economic Burden of Tuberculosis for Patients and their Households in Cochabamba, Bolivia. J Community Med Public Health 5: 227. DOI: 10.29011/2577-2228.100227

facility and who were for at least 14 days into the intensive or continuation treatment phase at the time of study. Ineligible patients were patients even if confirmed TB cases who had not started TB treatment yet or who had been in the treatment phase for less than two weeks at the time of the study. Children under 15 -years-old were excluded if without their guardian.

\section{Sampling}

A random sampling of health facilities as clusters was carried out. A weighted probability-proportional-to-size (PPS) cluster sampling technique was used. The number of notifications per cluster was available from the Tuberculosis Control Program TCP of the department of Cochabamba. In a selected health facility, all consecutive patients attending a follow-up visit, a DOT, or picking up drugs were enrolled until the required number has been obtained.

\section{Sample size calculation}

At the time of sampling, the total patient population being treated in the health services network was $n=764$. From that it was necessary to make a number of assumptions for the sample size calculation, using available information.

From a pilot study, the proportion of households experiencing catastrophic total costs due to TB illness $(\pi \mathrm{g})$ was estimated at $20 \%$. The relative precision around the estimate we'll drawn from the survey (d) was set to $4 \%$. The cluster effect (DEFF) was set to 2, based on similar studies conducted in other countries. Then required sample size was then $\mathrm{N}=512$, calculated with the following formula [11]:

$$
N=D E F F+\frac{1.96^{2} n(1-\pi g) \pi g}{d^{2}(n-1)+1.96^{2}(1-\pi g) \pi g}
$$

Since the calculated sample size represented a large proportion of the survey population of TB patients treated in the entire health network $(\mathrm{N}=512$ out of $\mathrm{n}=764)$, the sample size had to be corrected to account for the added precision gained by sampling a large percentage of the population, through the following formula:

$$
N_{F P C}=\frac{N}{1+\frac{N-1}{T}}
$$

Where $\mathrm{N}_{\mathrm{FPC}}$ stands for the finite population corrected sample size, and $\mathrm{T}$ is the size of the sampling frame of TB cases notified departmentally per year (764). The final calculated sample size was $\mathrm{N}_{\mathrm{FPC}}=308$ patients. We therefore managed to interview 310 individuals.

\section{Cluster Selection}

To determine the number of patients per cluster, the sample size 308 was divided by the number of clusters that were decided to take into account for the study $308 / 50=6$ new patients to be selected per cluster. In all selected health facilities, consecutive patients are enrolled in the survey until the required number of new cases is reached. Then the following steps were followed. a. A list of health facilities was established and their number of the TB patients at the time of the study (764), from which survey clusters were selected. $b$. The cumulative number of patients was calculated and recorded in an additional column. c. The sampling interval was determined: $764 / 50=15$. d. Using a random numbers table a number between 0 and 15 was selected. In this case, the number selected was 2 . e. The first cluster was selected using the number 2. Selection of the subsequent clusters was made by adding the sampling interval of 15 to this first number of 2 . Therefore, the second cluster selected in the center where the cumulative number of patients falls. The same procedure was done until the number of clusters set was completed.

\section{Data collection}

The generic survey instrument proposed by WHO for cost survey in TB the tuberculosis patients was used with a local adaptation of health care provider terminology (typologies and categories) in order to reflect local wordings [10]. Interviewed patients reported on expenditures retrospectively. Some patients were interviewed during the intensive treatment phase and others in the continuation treatment phase, and expenditure data were collected for that particular phase. Data collection during different treatment phases allowed to impute data of future and past costs during an entire illness episode. Such cross-sectional approach is easier to implement than a longitudinal study since most patients attend a facility during the study period can be enrolled into the survey and there is no need to identify patients for follow-up. This WHO survey instrument has four parts (Figure 1):

\section{Part I Patient information}

Part II Overview of TB treatments before current treatment (for re-treatment cases only)

Part III Costs before the current TB treatment (for cases in the intensive phase only)

Part IV Cost and coping during current TB/MDR-TB treatment (for all patients) 
Citation: Mattos MR, Illanes D, Avilez J, Trujillo W, Martin A, et al. (2021) Economic Burden of Tuberculosis for Patients and their Households in Cochabamba, Bolivia. J Community Med Public Health 5: 227. DOI: 10.29011/2577-2228.100227

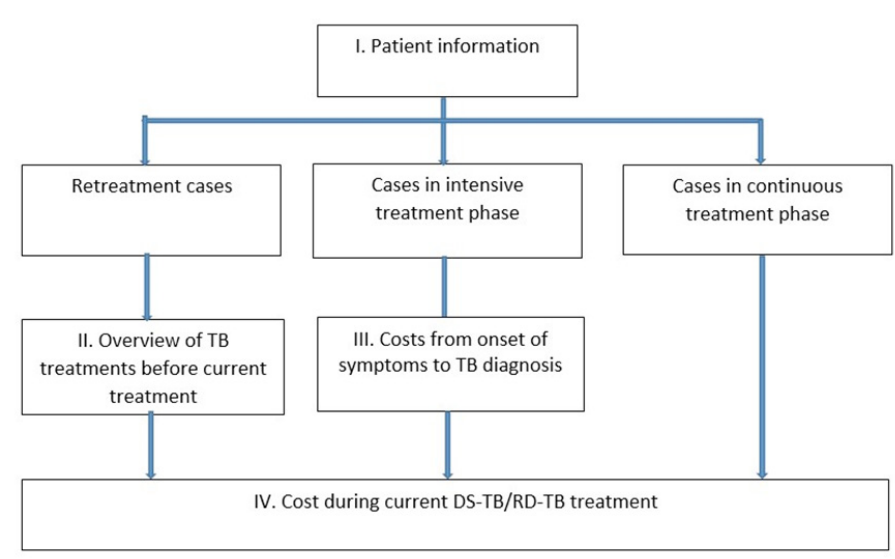

Figure 1: Interview instrument parts.

Patient information (Part I) and information about costs related to the current TB treatment (Part IV), were collected for all patients. Information about costs related to health seeking and diagnostic procedures before the person was registered as a TB patient (Part III) were collected only from patients who were in the intensive phase of either a 1st line treatment or a drug resistant. For patients who were interviewed during the continuous phase, information was collected only about costs related to the continuous phase.

Using the same procedure all previously treated cases were also interviewed questioned with brief summary questions on previous TB treatments (Part II). This was collected for previous treatments up to 2 years before starting of the present treatment episode. Information collected in part III from cases interviewed in the intensive phase, were used to impute data costs for patients interviewed in the continuation phase and for re-treatment cases. Similarly, information about costs in the continuation phase collected from patients interviewed in this phase, were used to project costs for patients interviewed in the intensive phase. The unit of analysis was the patient, but we also considered the economic consequences in the context of the patients' household. The costs were first analyzed using bolivianos the local currency, since it was the patients who provided the information directly. All amounts in local currency were converted to USD dollars. For this, we use the conversion rate for the year 2017 provided by the World Bank.

\section{Data Analysis}

First a descriptive analysis of the patient population was carried out regarding sociodemographic characteristics and TB treatment. Estimating cost. The most important direct medical payment, such as payments for medications, laboratory tests, consultation fees, etc. and direct non-medical payments such as payments for travel, food, etc. were calculated in a disaggregated manner. The remaining costs of the patient's current treatment phase were extrapolated from costs of patients who were in that treatment phase at the same health district and at the time of the study. The calculation of indirect costs for the entire TB episode was carried out through the results-based approach where the loss of income was calculated from the report of household income before TB episode and household income during the TB episode, multiplied by the duration of the entire episode. The household income was a self-reported household monthly income. Determining catastrophic costs. The percentage of households experiencing an economic burden or a total catastrophic cost, defined by a loss of at least $20 \%$ of annual income, was determined. For this, the total cost of the episode was calculated as direct costs plus indirect costs divided by the annual household income before the TB episode. Each household was given a binary value for whether or not they incurred catastrophic total costs due to TB. These binary values allowed a calculation of the percentage of TB respondents treated in health networks who incurred catastrophic total costs. These percentages were analyzed by income quintile, sex, type of TB and HIV status. Multivariable logistic regression modeling was used to find factors significantly associated with the risk of a total catastrophic cost for a TB patient. Data analyses were performed using SPSS 25.0 statistical software, and the statistical significance level was set to 0.05 .

\section{Ethical aspects}

The study protocol and the WHO adapted questionnaire were approved by the Ethics Review Committee of the Medical Faculty of Universidad Mayor de San Simón, Cochabamba, Bolivia [10]. All patients who agreed to be interviewed signed an informed consent form after receiving information about their rights.

\section{Results}

A total of 310 patients were interviewed, including 183 (59\%) men and 127 women (41\%). Out of these cases, 237 were diagnosed with pulmonary tuberculosis $(76.4 \%)$, and 73 with extra pulmonary tuberculosis $(23.6 \%)$, and $17(5.5 \%)$ patients were HIV positive. There were $282(91 \%)$ new TB cases, $17(5.5 \%)$ retreats and $10(3.5 \%)$ multidrug resistant. Also, $236(76.1 \%)$ were in the continuation phase and $74(23.9 \%)$ in the intensive phase. Table 1 presents the socioeconomic and TB-related information for each subgroup of patients according to the TB type and for the whole study group. 
Citation: Mattos MR, Illanes D, Avilez J, Trujillo W, Martin A, et al. (2021) Economic Burden of Tuberculosis for Patients and their Households in Cochabamba, Bolivia. J Community Med Public Health 5: 227. DOI: 10.29011/2577-2228.100227

\begin{tabular}{|c|c|c|c|c|c|c|c|c|}
\hline \multirow[t]{2}{*}{ Characteristes } & \multicolumn{2}{|c|}{ MDR-TB $^{\text {a }}$} & \multicolumn{2}{|c|}{ DS-TB $^{\text {b }}$} & \multicolumn{3}{|c|}{ Retreatment } & \multirow{2}{*}{$\begin{array}{l}\text { All } \\
(\%)\end{array}$} \\
\hline & $\mathbf{N}$ & $(\%)$ & $\mathbf{N}$ & $(\%)$ & $\mathbf{N}$ & $(\%)$ & $\mathbf{N}$ & \\
\hline \multicolumn{9}{|l|}{ Sex } \\
\hline Male & 7 & $70.00 \%$ & 176 & $58.70 \%$ & 13 & $76.50 \%$ & 183 & $59.00 \%$ \\
\hline Female & 3 & $30.00 \%$ & 124 & $41.30 \%$ & 4 & $23.50 \%$ & 127 & $41.00 \%$ \\
\hline \multicolumn{9}{|l|}{ Age group } \\
\hline $0-14$ & 0 & $0.00 \%$ & 4 & $1.30 \%$ & 0 & $0.00 \%$ & 4 & $1.30 \%$ \\
\hline $15-24$ & 4 & $40.00 \%$ & 81 & $27.10 \%$ & 3 & $17.60 \%$ & 85 & $27.50 \%$ \\
\hline $25-34$ & 1 & $10.00 \%$ & 59 & $19.70 \%$ & 3 & $17.60 \%$ & 60 & $19.40 \%$ \\
\hline $35-44$ & 1 & $10.00 \%$ & 37 & $12.40 \%$ & 1 & $5.90 \%$ & 38 & $12.30 \%$ \\
\hline $45-54$ & 3 & $30.00 \%$ & 27 & $9.00 \%$ & 3 & $17.60 \%$ & 30 & $9.70 \%$ \\
\hline $55-64$ & 0 & $0.00 \%$ & 26 & $8.70 \%$ & 2 & $11.80 \%$ & 26 & $8.40 \%$ \\
\hline $65+$ & 1 & $10.00 \%$ & 65 & $21.70 \%$ & 5 & $29.40 \%$ & 66 & $21.40 \%$ \\
\hline \multicolumn{9}{|l|}{ Treatment Phase } \\
\hline Intensive & 3 & $30.00 \%$ & 71 & $23.70 \%$ & 3 & $17.60 \%$ & 74 & $23.90 \%$ \\
\hline Continuation & 7 & $70.00 \%$ & 229 & $76.30 \%$ & 14 & $82.40 \%$ & 236 & $76.10 \%$ \\
\hline \multicolumn{9}{|l|}{ Recorded HIV Status } \\
\hline Positive & 1 & $10.00 \%$ & 16 & $5.30 \%$ & 0 & $0.00 \%$ & 17 & $5.50 \%$ \\
\hline Negative & 9 & $90.00 \%$ & 273 & $91.00 \%$ & 17 & $100.00 \%$ & 282 & $91.00 \%$ \\
\hline Unknown & 0 & $0.00 \%$ & 11 & $3.70 \%$ & 0 & $0.00 \%$ & 11 & $3.50 \%$ \\
\hline \multirow{2}{*}{$\begin{array}{l}\text { Type of TB } \\
\text { Pulmonary }\end{array}$} & & & & & & & & \\
\hline & 9 & $90.00 \%$ & 228 & $76.50 \%$ & 16 & $94.10 \%$ & 237 & $76.90 \%$ \\
\hline Extra-pulmonary & 1 & $10.00 \%$ & 70 & $23.50 \%$ & 1 & $5.90 \%$ & 71 & $23.10 \%$ \\
\hline \multicolumn{9}{|l|}{$\begin{array}{l}\text { Patient's education } \\
\text { status }\end{array}$} \\
\hline Illiterate & 0 & $0.00 \%$ & 1 & $0.40 \%$ & 0 & $0.00 \%$ & 1 & $0.30 \%$ \\
\hline Primary school & 1 & $11.10 \%$ & 47 & $16.70 \%$ & 1 & $7.10 \%$ & 48 & $16.50 \%$ \\
\hline Secondary school & 0 & $0.00 \%$ & 105 & $37.20 \%$ & 7 & $50.00 \%$ & 105 & $36.10 \%$ \\
\hline High school & 7 & $77.80 \%$ & 114 & $40.40 \%$ & 5 & $35.70 \%$ & 121 & $41.60 \%$ \\
\hline University and higher & 1 & $11.10 \%$ & 15 & $5.30 \%$ & 1 & $7.10 \%$ & 16 & $5.50 \%$ \\
\hline
\end{tabular}

Table 1: Characteristics of participants to the present research on costs incurred by tuberculosis patients in Cochabamba, Bolivia, 2017. 
Citation: Mattos MR, Illanes D, Avilez J, Trujillo W, Martin A, et al. (2021) Economic Burden of Tuberculosis for Patients and their Households in Cochabamba, Bolivia. J Community Med Public Health 5: 227. DOI: 10.29011/2577-2228.100227

Direct medical and non-medical costs the direct medical and non-medical costs incurred by the patient before diagnosis and during treatment are described in Table 2. The costs before diagnosis that were mainly direct medical costs, such as costs of radiography and/ or laboratory test, had a median of USD 9.5, and medicines costs had a median USD 7.4 in the whole group of patients. For patients in retreatment, this median cost was USD 12.4.

During the intensive phase treatment, direct medical costs were mainly due to hospitalization with a median of USD 4.4 in the whole group patients. The median costs related to radiography, laboratory test and medicines were USD 0 . Regarding the non-medical costs related to this same phase, they were mainly linked to DOT with a median USD 419.8 due to transport costs and a median of USD 94.5 for food and drinks costs. Moreover, the costs due to the consumption of nutritional supplements had a median of USD 249.1 and that of additional food outside the regular diet had a median USD 519 within the whole group of patients.

In the continuation phase, the most important direct medical costs were for hospitalization with a median of USD 57.3, especially in drug-susceptible or multidrug-resistant TB patients. The most important direct non-medical costs were related to DOT; transport had a median cost of USD 108.6, food and drinks had a median of USD 54.8. Nutritional supplements had a median cost of USD 249.1, and additional food to the regular diet had a median cost of USD 519.

\begin{tabular}{|c|c|c|c|c|}
\hline \multicolumn{5}{|c|}{ Type of Tuberculosis patients } \\
\hline & DS-TB ${ }^{b}$ & MDR-TB ${ }^{a}$ & Retreat & All \\
\hline & $\left(\mathrm{In} \mathrm{USD}^{\mathrm{c}}\right)$ & $\left(\mathrm{In} \mathrm{USD}^{\mathrm{c}}\right)$ & $\left(\operatorname{In} \mathrm{USD}^{\mathrm{c}}\right)$ & $\left(\right.$ In USD $\left.{ }^{c}\right)$ \\
\hline Costs & $\mathrm{n}=300$ & $\mathrm{n}=10$ & $\mathrm{n}=17$ & $\mathrm{n}=310$ \\
\hline \multicolumn{5}{|l|}{ Before the diagnosis } \\
\hline \multicolumn{5}{|l|}{ Medical } \\
\hline Consultation fee & 0.7 & 0.7 & 5.1 & 0.7 \\
\hline Radiography & 9.5 & 1.7 & 12.4 & 9.5 \\
\hline Lab test fees & 0.7 & 0.7 & 0.7 & 0.7 \\
\hline Other Procedures & 3.6 & 0 & 3.6 & 3.6 \\
\hline Medicines & 9.5 & 0.7 & 9.5 & 7.4 \\
\hline Other medical costs & 0.7 & 0.7 & 0.7 & 0.7 \\
\hline \multicolumn{5}{|l|}{ No Medical } \\
\hline Travel & 2 & 2.2 & 2.2 & 2.2 \\
\hline Food and drinks & 0.7 & 0.2 & 0.1 & 0.2 \\
\hline \multicolumn{5}{|l|}{ During the treatment } \\
\hline \multicolumn{5}{|l|}{ Intensive Phase } \\
\hline \multicolumn{5}{|l|}{ Medical } \\
\hline Consultation fee & 0 & 0 & 0.2 & 0 \\
\hline Other medical costs & 1.3 & 0 & 1.3 & 1.3 \\
\hline Hospitalization & 4.4 & 0 & 0 & 4.4 \\
\hline \multicolumn{5}{|l|}{ No Medical } \\
\hline \multicolumn{5}{|l|}{ DOT } \\
\hline Transport & 84 & 419.8 & 166.2 & 419.8 \\
\hline
\end{tabular}


Citation: Mattos MR, Illanes D, Avilez J, Trujillo W, Martin A, et al. (2021) Economic Burden of Tuberculosis for Patients and their Households in Cochabamba, Bolivia. J Community Med Public Health 5: 227. DOI: 10.29011/2577-2228.100227

\begin{tabular}{|c|c|c|c|c|}
\hline Food and drinks & 50.2 & 94.5 & 166.2 & 94.5 \\
\hline \multicolumn{5}{|l|}{ Picked up drugs } \\
\hline Food and drinks & 11.7 & 0 & 18.7 & 11.7 \\
\hline \multicolumn{5}{|c|}{ Follow-up medical outpatient visit } \\
\hline Transport & 0.8 & 0.2 & 0.9 & 0.8 \\
\hline \multicolumn{5}{|l|}{ Nutritional supplements } \\
\hline Nutritional supplements & 249.1 & 0 & 249.1 & 249.1 \\
\hline Food outside regular diet & 519 & 0 & 519 & 519 \\
\hline \multicolumn{5}{|l|}{ Continuous Phase } \\
\hline \multicolumn{5}{|l|}{ Medical } \\
\hline Consultation fee & 0 & 0 & 0.2 & 0 \\
\hline Other medical costs & 1.3 & 0.6 & 1.3 & 1.3 \\
\hline Hospitalization & 57.3 & 0 & 57.3 & 0 \\
\hline \multicolumn{5}{|l|}{ No Medical } \\
\hline \multicolumn{5}{|l|}{ DOT } \\
\hline Transport & 81.6 & 108.6 & 139.9 & 108.6 \\
\hline Food and drinks & 83.5 & 54.8 & 167.9 & 54.8 \\
\hline \multicolumn{5}{|l|}{ Picked up drugs } \\
\hline Transport & 7 & 0 & 14 & 7 \\
\hline Food and drinks & 3.5 & 0 & 7 & 3.5 \\
\hline \multicolumn{5}{|c|}{ Follow-up medical outpatient visit } \\
\hline Transport & 15.6 & 0 & 15.6 & 15.6 \\
\hline Accommodation & 32.4 & 0 & 32.4 & 32.4 \\
\hline \multicolumn{5}{|l|}{ Nutritional supplements } \\
\hline Nutritional supplements & 249.1 & 747.4 & 249.1 & 249.1 \\
\hline Food outside regular diet & 519 & 1382.7 & 519 & 519 \\
\hline
\end{tabular}

Table 2: Median of direct medical and non-medical costs incurred by patients with tuberculosis before the diagnosis and during treatment in 2017, the time of the study in, Cochabamba, Bolivia. 
Citation: Mattos MR, Illanes D, Avilez J, Trujillo W, Martin A, et al. (2021) Economic Burden of Tuberculosis for Patients and their Households in Cochabamba, Bolivia. J Community Med Public Health 5: 227. DOI: 10.29011/2577-2228.100227

\section{Total direct and indirect costs}

The total direct and indirect costs are detailed in Table 3. Median total costs of an episodes were USD 1211.4 in the whole group. It was USD 855.6, for drug-susceptible patients, USD 932.2 for retreated patients, and USD 11873.2 for multidrug resistant patients. Indirect costs were more important than direct medical and non-medical costs in the whole group of TB patients; with a median of USD 768.1 , the indirect cost corresponded to $63.4 \%$ of the total costs. In the MDR-TB patients, indirect costs were also higher that direct costs, had they had a median of USD 6454.8 , corresponded to $54.3 \%$ of the total costs. Direct non-medical costs were also important with a median in the whole group of USD 408.7 (33.7\%), and with a median of USD 5399.6 (45.4\%) in MDR-TB patients.

\begin{tabular}{|c|c|c|c|c|}
\hline & & $\begin{array}{l}\text { Type of tuberculosis } \\
\text { patients }\end{array}$ & & \\
\hline & DS-TB $^{\mathrm{b}}$ (In USDc) & MDR-TBa Retreat & All (In USD $\left.{ }^{c}\right)$ & $\left(\operatorname{In~USD}^{c}\right)\left(\right.$ In USD $\left.{ }^{c}\right)$ \\
\hline Costs & $\mathrm{n}=300$ & $\mathrm{n}=10$ & $\mathrm{n}=17$ & $n=310$ \\
\hline \multicolumn{5}{|l|}{ Direct } \\
\hline Medical & $34.7(40 \%)$ & $18.8(0.1 \%)$ & $28.9(3.1 \%)$ & $34.7(2.8 \%)$ \\
\hline No medical & $242.3(28.3 \%)$ & $5399.6(45.4 \%)$ & $275.6(29.5 \%)$ & $408.7(33.7 \%)$ \\
\hline Indirect & $578.5(67.6 \%)$ & $6454.8(54.3 \%)$ & $627.7(67.3 \%)$ & $768.1(63.4 \%)$ \\
\hline Total & 855.6 & 11873.2 & 932.2 & 1211.4 \\
\hline
\end{tabular}

Table 3: Median of total costs (direct and indirect) incurred by tuberculosis patients enrolled in 2017 in Cochabamba, Bolivia.

\section{Catastrophic costs}

Out of the 310 patients, 136 (43.87\%) incurred catastrophic costs. Table 4 shows the proportion of patients experiencing catastrophic costs according to demographic characteristics. Proportion of TB patients incurring catastrophic costs increased with age, even reaching more than $50 \%$ in people older than over 55 years. Six out of ten MDR-TB patients suffered catastrophic costs and $63 \%$ of poor patients also experiencing catastrophic costs.

\begin{tabular}{|c|c|c|c|c|}
\hline \multirow[t]{2}{*}{ Characteristics } & \multirow[b]{2}{*}{ Yes } & \multicolumn{3}{|c|}{ Catastrophic cost incurred (n) } \\
\hline & & $\%$ & No & $\%$ \\
\hline All patients & 136 & $43.80 \%$ & 174 & $56.20 \%$ \\
\hline \multicolumn{5}{|l|}{ Age group } \\
\hline $0-14$ & 2 & $50.00 \%$ & 2 & $50.00 \%$ \\
\hline $15-24$ & 29 & $34.10 \%$ & 56 & $65.90 \%$ \\
\hline $25-34$ & 22 & $36.70 \%$ & 38 & $63.30 \%$ \\
\hline $35-44$ & 18 & $47.40 \%$ & 20 & $52.60 \%$ \\
\hline $45-54$ & 14 & $46.70 \%$ & 16 & $53.30 \%$ \\
\hline $55-64$ & 14 & $53.80 \%$ & 12 & $46.20 \%$ \\
\hline $65+$ & 37 & $56.10 \%$ & 29 & $43.90 \%$ \\
\hline \multicolumn{5}{|l|}{ Sex } \\
\hline Male & 88 & $48.10 \%$ & 95 & $51.90 \%$ \\
\hline Female & 48 & $37.80 \%$ & 79 & $62.20 \%$ \\
\hline
\end{tabular}


Citation: Mattos MR, Illanes D, Avilez J, Trujillo W, Martin A, et al. (2021) Economic Burden of Tuberculosis for Patients and their Households in Cochabamba, Bolivia. J Community Med Public Health 5: 227. DOI: 10.29011/2577-2228.100227

\begin{tabular}{|l|c|c|c|c|}
\hline DR-TB Status & & & & \\
\hline MDR-TB & 6 & $60.00 \%$ & 170 & $40.00 \%$ \\
\hline DS-TB & 130 & $43.30 \%$ & & $56.70 \%$ \\
\hline HIV Status & & & 10 & $58.80 \%$ \\
\hline HIV positive & 7 & $41.20 \%$ & 157 & $55.70 \%$ \\
\hline HIV negative & 125 & $44.30 \%$ & 39 & $60.90 \%$ \\
\hline Income Quintile & & & 28 & $36.80 \%$ \\
\hline Poorest & 25 & $39.10 \%$ & 38 & $58.50 \%$ \\
\hline Less Poor & 48 & $63.20 \%$ & 27 & $58.70 \%$ \\
\hline Average & 27 & $41.50 \%$ & 36 & $76.60 \%$ \\
\hline Less Wealthy & 19 & $41.30 \%$ & $23.40 \%$ & \\
\hline Wealthiest & 11 & & & \\
\hline
\end{tabular}

Table 4: Characteristics of patients experiencing catastrophic costs for tuberculosis in 2017 in Cochabamba, Bolivia.

\section{Factors independently associated with catastrophic costs}

Table 5 shows the factors independently associated with catastrophic costs. In the final logistic regression model, factors showing a significant multivariate association with higher catastrophic costs occurrence were living in an urban province (OR $=1.8295 \% \mathrm{CI}, 1.11$ to $2.98, \mathrm{P}=0.0016$ when compared to a rural province) being older than 55 years. ( $\mathrm{OR}=1.21 \% \mathrm{CI}, 1.07$ to $1.38, \mathrm{P}=0.005)$, and to have a lower income. (high income compared to low income, $\mathrm{OR}=0.83,95 \% \mathrm{CI}$ : 0.69 to $0.99, \mathrm{P}=0.049$ ).

\begin{tabular}{|l|c|c|c|c|}
\hline & & Catastrophic costs & & \\
\hline Characteristics & $\mathrm{B} \pm \mathrm{SE}$ & OR & 1.11 to 2.98 & $\mathrm{PI}$ \\
\hline Living an urban province & $0.60 \pm 0.25$ & 1.82 & 1.07 to 1.38 & 0.016 \\
\hline Age $>55$ years & $0.19 \pm 0.06$ & 1.21 & 0.69 to 0.99 & 0.003 \\
\hline High income & $-0.18 \pm 0.09$ & 0.83 & 0.049 \\
\hline
\end{tabular}

Table 5: Factors independently associated with catastrophic costs using a logistic regression model in tuberculosis patients treated in 2017 in Cochabamba, Bolivia.

\section{Discussion}

\section{Key findings}

The results of this research suggest that patients with TB treated in the health services network of Cochabamba, Bolivia, face a great financial burden as a result of the disease. This affects the most vulnerable stratum of society. Before the beginning of the diagnosis when seeking health care, more medical direct costs are observed, especially by radiography and medicines [12], these costs decrease during treatment, probably because the coverage of the health system allows avoiding these costs when the patient is already diagnosed $[12,13]$. During the treatment, both in the intensive phase and in the continuation, the most important costs were those related to transport and food due to the administration of the DOT [13], due to the fact that many people have to travel long distances and even consume food outside the home to receive their treatment in the health center. In addition, there are costs for nutritional supplements and additional foods to the regular diet that patients must incur to improve their 272 general condition by medical prescription or own initiative [14]. Indirect costs were the highest in the entire TB episode [6], mainly due to the loss of income due to TB $[15,16]$ especially in MDR-TB patients $[17,18]$. More than $43.8 \%$ of patients suffer a catastrophic cost with a loss greater than $20 \%$ of the annual economic income. Older patients have more difficulties to generate economic income $[19,20]$ but age was also a factor independent of income in multiple logistic regression, reflecting maybe increasing absolute indirect costs with age. MDR-TB patients whose duration of treatment is longer 
Citation: Mattos MR, Illanes D, Avilez J, Trujillo W, Martin A, et al. (2021) Economic Burden of Tuberculosis for Patients and their Households in Cochabamba, Bolivia. J Community Med Public Health 5: 227. DOI: 10.29011/2577-2228.100227

[17] experienced also catastrophic costs (6 out of ten), population where the economic burden due to illness is greater [18].

\section{Limitations of the study}

The main challenge when estimating total costs incurred by a patient is the recall bias, that predominantly affects cost estimates for the pre-treatment period. Nevertheless, the used approach to only interview persons in the intensive phase about diagnostics costs intended to minimize this type of bias. Likewise, given that patients are only interviewed once, many of their costs have to be estimated. On the other hand, although self-reported income can be unreliable, especially in settings where informal economy dominates such as in Bolivia the use of an asset score allows to make a more accurate estimation of house income but we lack of information to estimate such an asset score. Finally, the direct and indirect costs of TB for the patients and their households can be extended well beyond the treatment period, even for people who are declared cured. Additionally, measures of costs need to have a longer-term time-window for the documentation of long-term needs of social and economic support for TB-affected households.

\section{Recommendations}

Due to the serious impact of TB-related costs on the wellbeing of the home, the inclusion of TB services in national health insurance and food and transportation subsidies plans, is recommended. In the work place, it is recommended to generate public policies to achieve labor immobility until healing, and to increase efforts to find cases early to reduce indirect costs related to the inability to work. The results of the study indicate the need for the State to protect its population from the economic and health effects of contracting TB, and in this way, to prevent an increase or deepening of poverty among those suffering from the disease. There is a need to continue researching using methods that allow you to calculate costs and revenues more accurately.

\section{Conclusions}

The results of this study are similar to those shown by other TB patients in other parts of the world, with TB patients especially facing a great financial burden, without sufficient social protection. Therefore, the free diagnosis and treatment of TB is not sufficient to alleviate the vulnerability of financial constraints due to the disease. Most of the costs before diagnosis were direct medical due to radiographies and medicines. With respect to the direct non-medical costs incurred by the patients during the treatment, both in the intensive phase and in the continuation phase, the most important costs were related to transport and food by the DOT and the costs for nutritional supplements and additional foods to the regular diet. The total costs were high, indirect costs being the highest in the entire episode of TB compared to direct medical and non-medical costs, and mainly due to the loss of income because of the disease being even higher in TB-MDR patients. $43.87 \%$ of the patients in the study incurred catastrophic costs with more than $60 \%$ in patients older than 55 years, with MRD-TB, and in less poor patients. The three factors associated with higher catastrophic costs for patients were to live an urban area, to be older than 55 years and to have a low income.

\section{References}

1. Bloom BR. (2018) A Neglected Epidemic. N Engl J Med, 378: 291-293.

2. Global tuberculosis report 2020. Geneva: World Health Organization; 2020.

3. Mattos MR, Illanes D, Avilez J, Trujillo W, Robert A. (2019) Spatial distribution of Tuberculosis and socioeconomic inequalities in Cochabamba, Bolivia. Journal of Community Medicine \& Public Health. 3: $1-10$.

4. Ledo C, Soria R. (2011) [The health system of Bolivia]. Salud Publica Mex.53: s109-19.

5. Tuberculosis M. (2017) Manual de Normas en Tuberculosis.

6. Tanimura T. (2014) Financial burden for tuberculosis patients in lowand middle-income countries: a systematic review. Eur Respir J, 43: 1763-1775.

7. Lambert ML. (2005) Delays to treatment and out-of-pocket medical expenditure for tuberculosis patients, in an urban area of South America. Ann Trop Med Parasitol, 99: 781-787.

8. Mauch V. (2013) Free tuberculosis diagnosis and treatment are not enough: patient cost evidence from three

9. $\quad$ continents. Int J Tuberc Lung Dis. 17: 381-387.

10. Organization WH. (2015) The End of TB Strategy.

11. World Health Organization, G.T.P., Protocol for survey to determine direct and indirect costs due to TB and to estimate proportion of TB affected households experiencing catastrophic total costs due to TB Field testing version. 2015.

12. http://samplesize.herokuapp.

13. Mauch V. (2013) Tuberculosis patients in the Dominican Republic face severe direct and indirect costs and need social protection. Rev Panam Salud Publica. 33: 332-339.

14. Aspler A. (2008) Cost of tuberculosis diagnosis and treatment from the patient perspective in Lusaka, Zambia. Int J Tuberc Lung Dis. 12: 928-935.

15. Kemp JR. (2007) Can Malawi's poor afford free tuberculosis services? Patient and household costs associated with a tuberculosis diagnosis in Lilongwe. Bull World Health Organ. 85: 580-585.

16. Guzman-Montes GY, Ovalles RH, Laniado-Laborin R. (2009) Indirect patient expenses for antituberculosis treatment in Tijuana, Mexico: is treatment really free? J Infect Dev Ctries. 3: 778-782.

17. Rajeswari R. (1999) Socio-economic impact of tuberculosis on patients and family in India. Int J Tuberc Lung Dis. 3: 869-877.

18. Rouzier VA. (2010) Patient and family costs associated with tuberculosis, including multidrug-resistant tuberculosis, in Ecuador. Int J Tuberc Lung Dis. 14: 1316-1322. 
Citation: Mattos MR, Illanes D, Avilez J, Trujillo W, Martin A, et al. (2021) Economic Burden of Tuberculosis for Patients and their Households in Cochabamba, Bolivia. J Community Med Public Health 5: 227. DOI: 10.29011/2577-2228.100227

19. Walcott RL. (2020) There's no such thing as a free TB diagnosis: Catastrophic TB costs in Urban Uganda. Glob Public Health, 2020: 1-12.

20. Hoa NB. (2011) Household expenditure and tuberculosis prevalence in VietNam: prediction by a set of household indicators. Int $\mathrm{J}$ Tuberc Lung Dis. 15: 32-37.
21. Muniyandi M. (2019) Catastrophic costs due to tuberculosis in South India: comparison between active and passive case finding. Trans $\mathrm{R}$ Soc Trop Med Hyg. 